\title{
ANOMALIA EM GÔNADAS DE PARATI Mugil curema VALENCIENNES, 1836. (PISCES - MIGILIDAE)
}

\author{
${ }^{*}$ Daura Regina de Brito Eiras \\ ${ }^{*}$ Rita Pinoti
}

\begin{abstract}
:
Aberrant gonadal development was observed in two females of Mugil curema Valenciennes, 1836 (Mugilidae) collected in Paranaguá Bay (Paraná - Brasil). Collections were taken from november of 1983 to february of 1985 , comprising a total of 1020 individuals. This work describes and illustrates the observed malformation.
\end{abstract}

\section{INTRODUÇÃO:}

A família Mugilidae se apresenta amplamente distribuida no mundo, sendo encontrada tanto em águas tropicais como subtropicais, dando preferência a regiões costeiras e estuarinas. O parati Mugil curema Val. 1836, ocorre no Pacífico leste e em ambos os lados do Atlântico, sendo talvez o representante mais comum da fam ília Mugilidae encontrado no litoral brasileiro (Menezes, 1983).

Devido a sua abundância e valor comercial relativos, vários trabalhos vêm sendo realizados com a espécie. Furtado, em 1968 forneceu dados sobre a alimentação de indivíduos na fase jovem. Couto \& Nascimento (1980 a) estudaram aspectos da biologia reprodutiva de Mugil curema nos estuários de Pernambuco. Mendes (1983) realizou testes de aclimatação de alevinos da espécie à água doce. Fanta Feofiloff at allii (no prelo), descreveram as alterações no comportamento e os limites letais de paratis juvenis sob diferentes salinidades e temperaturas.

Os ovários da espécie são estruturas pares encontradas no interior da cavidade abdominal, revestidas externamente por uma teca (externa) de tecido conjuntivo denso. Internamente, encontramos uma outra teca (interna) de tecido conjuntivo flácido, a qual divide o ovário em compartimentos onde estão abrigados os ovócitos. Os ovários são suspensos por um mesentério denominado mesovário e, próximo ao poro urogenital, se comunicam com o exterior através de um oviduto. A nutrição dos ovócitos é feita por pequenas artérias e veius localizadas na teca externa que levam a alimentação aos compartimentos e daí, por meio de osmose, aos ovócitos.

0 presente trabalho registra a ocorrência de dois casos anômalos em gônadas de Mugil curema Val. 1836 - Fam ilia Mugilidae.

\footnotetext{
*Professora do Centro de Biologia Marinha - UFPr

* Estagiária do Centro de Biologia Marinha - UFPr
} 


\section{MATERIAL E MÉTODOS:}

Ao longo de 15 meses consecutivos (novembro/1983 a fevereiro/1985), foram feitos estudos de biologia da reprodução em 1020 exemplares de parati Mugil curema Val. 1836, coletados por meio de arrastão de praia em Pontal do Sul Baia de Paranaguá, no litoral paranaense. No decorrer deste trabalho, foram encontrados dois exemplares da espécie com formação anômala das gônadas.

Estes peixes foram capturados no período da manhã, com aux'lio de uma rede de arrasto medindo $150 \mathrm{~m}$ de comprimento por $04 \mathrm{~m}$ de largura, com malhas 5 e 6.

Imediatamente após a coleta, os indivíduos foram levados ao laboratório para manuseio à fresco.

Após identificação dos mesmos a nivel de espécie, foram retirados dados de: comprimento total (cm), por meio de um ictiômetro, considerando-se desde a extremidade anterior do focinho até o final da nadadeira causal levemente distendida e, peso total (milésimos de grama), com auxílio de uma balança de precisão OWALABOR.

Através de incisão longitudinal na cavidade abdominal, partindo do poro urogenital em sentido postero-anterior, as gônadas foram expostas, verificando-se a anomalia em dois dos 1020 exemplares coletados.

Por observação macroscópica das gônadas foi determinado o sexo, o estádio de maturação sexual e o peso da gônada (precisão de milésimo de grama).

Do primeiro exemplar anômalo também foi feita a medição do comprimento total da gônada e das porções cefálica, mediana e caudal com auxílio de paquímetro. Em seguida esta gônada foi fixada em líquido conservador Bolles Lee e mais tarde fotografada.

\section{RESULTADOS:}

0 primeiro peixe encontrado com formação anômala foi capturado em 05 de dezembro de 1984. Apresentava comprimento total $(\mathrm{Lt})$ de $24.9 \mathrm{~cm}$, peso total (Wt) de $150.745 \mathrm{~g}$ e as gônadas, identificadas como femininas, pesavam (Wg) 20.800 g e mediam $8.1 \mathrm{~cm}$ de comprimento total, sendo registrados $2.3 \mathrm{~cm}, 3.1 \mathrm{~cm}$ e $2.7 \mathrm{~cm}$ para as porções cefálica, mediana e caudal, respectivamente.

$\mathrm{O}$ segundo peixe anômalo, também uma fêmea, foi capturado na semana seguinte (12.12.84), apresentando o mesmo tipo de mal-formação dos ovários, $\operatorname{com~} \mathrm{Lt}=23.5 \mathrm{~cm}, \mathrm{Wt}=125.092 \mathrm{~g} \mathrm{e} \mathrm{Wg}=14.988 \mathrm{~g}$.

Estes peixes apresentavam os ovários túrgidos, com coloração amarelo vivo, sendo possível a visualização de óvulos individualizados no seu interior. Reforçando ainda, os ovários ocupavam quase que totalmente a cavidade abdominal indicando um estádio de maturação avançado (estádio III), segundo escala descrita por Couto \& Nascimento (1980 b) para a mesma espécie.

Em cada um dos exemplares, o ovário esquerdo e direito se apresentou fusionado na porção mediana, estando o flanco da vascularização formado por dobras grosseiras e o outro, inteiramente liso. As porções cefálica e causal da gônada se apresentaram pareadas, ou seja, normais (Fig. 1 e 2). 


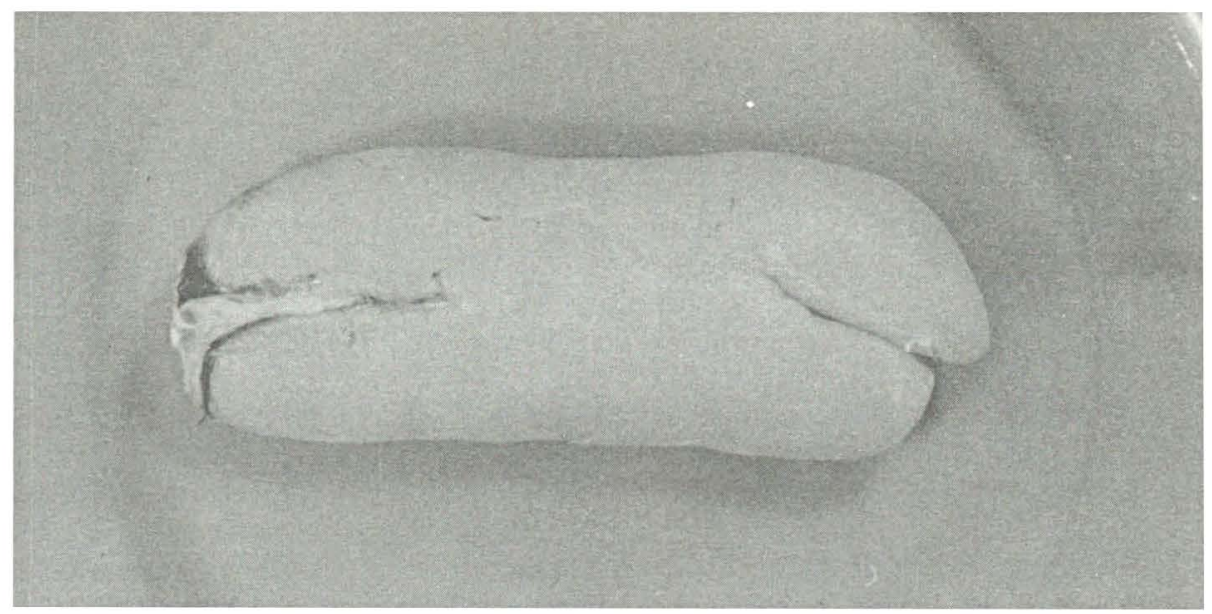

Figura 1 - Fusão anômala da porção mediana da gônada de Mugil curema (Flanco não vascularizado)

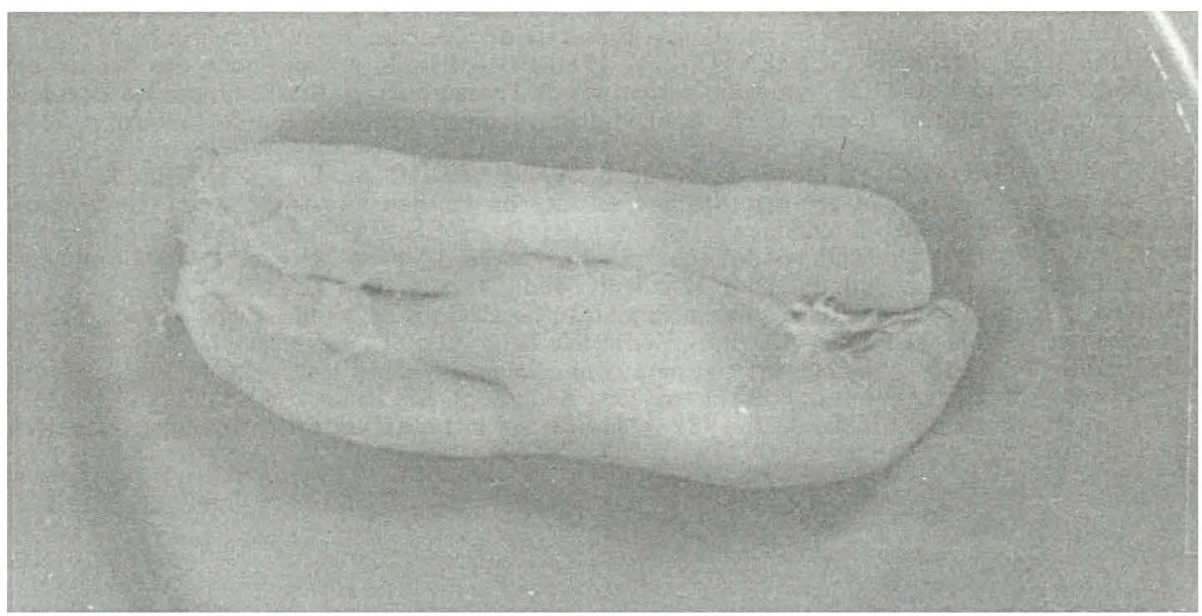

Figura 2 - Dobras anômalas da gônada de Mugil curema|(Flanco vascularizado)

\section{RESUMO:}

Em 1020 exemplares de parati Mugil curema Val. 1836, coletados na Baia de Paranaguá (Paraná - Brasil), durante 15 meses consecutivos, foram encontrados dois exemplares femeas em dezembro de 1984 com formação anômala das gônadas. 0 presente trabalho ilustra e descreve o tipo de mal-formação encontrada. 


\section{BIBLIOGRAFIA:}

BROWN, M. E., ed. 1957 - The Physiology of Fishes. Acad. Press Inc., New York, 1:287-359.

CATO, J. C. \& McCULLOUGH, W. E., ed. 1976 - Economics, biology and food technology of mullet. Horida Sea Grant Program, (15):159p.

COUTO, L. M. M. \& NASCIMENTO, I. V. 1980 (a) - Reprodução da tainha Mugil curema Valenciennes, 1836, em águas estuarinas de Pernambuco, Brasil. Congresso Brasileiro de Aquicultura I. Recife, 1978. Academia Brasileira de Ciências. Rio de Janeiro, p. 205-211.

COUTO, L. M. M. \& NASCIMENTO, I. V. 1980 (b) - Estudo microscópico dos ovários de Mugil curema Val. 1836, em águas estuarinas de Pernambuco - Brasil. Congresso Brasileiro de Aquicultura I. Recife 1978. Academia Brasileira de Ciências. Rio de Janeiro, p. 213219.

FANTA-FEOFILOFF, E.; EIRAS, D. R de B.; BOSCARDIM, A. T. ; KRAMBECK, M. L. (no prelo) - Effect of temperature and salinity on the behavior and oxygen consume of Mugil curema (Pisces - Mugilidae).

FURTADO, E. 1968 - Alguns dados sobre a alimentação de jovens do gênero Mugil Linnaeus no Estado do Ceará. Arq. Est. Biol. Mar. Univ. Fed. Ceará, 8 (2): $173-176$.

MENDES, E. N. 1983 - Estudo sobre aclimatação de alevinos de tainha Mugil curema Valenciennes, 1836, à água doce. Rev. Bras. Zool., São Paulo (2) 1:13-33.

MENEZES, N. A. 1983 - Guia prático para conhecimento e identificação das tainhas e paratis (Pisces - Mugilidae) do litoral brasileiro. Rev. Bras. Zool. São Paulo 2 (1): 1-12.

MOYLE, P. B. \& CECH Jr, J. J. 1982 - Fishes: An introduction to ichthyology. PrenticeHall, Inc., 593 p. 